\title{
Earth Systems Thinking: Global Consumerism, Climate Change, and the Spiritual Value of the Earth
}

\author{
G. D. Bothun \\ Department of Physics, University of Oregon, Eugene OR 97401, USA \\ E-mail: dkmatter@uoregon.edu
}

Received: April 4, 2018 Accepted: April 29, 2018 Published: May 22, 2018

doi:10.5296/emsd.v7i3.13179 URL: https://doi.org/10.5296/emsd.v7i3.13179

\begin{abstract}
In this paper we consider the root cause of climate change to be the industrial waste heat by product of increasing global consumption. The embodied energy associated with the conversion of Earth's resources into consumer goods has largely been driven by fossil fuel based energy. Using available data, we show how a) the rate of annual $\mathrm{CO}_{2}$ emissions to the atmosphere is increasing, b) the land+sea temperature anomaly index is increasing, particularly the last 3 years, c) the rate of heat addition to the world's oceans is also accelerating as this is in direct response to a globally increasing consumption per capita. In short, all of our human induced rates related to consumption are accelerating with increasingly severe consequences to the Earth system that maintains us. This is occurring amidst the reality that humans are in a necessary physical partnership with nature. Despite this, many human cultures have pursued dominance over the Earth's resources. This dominance is asserted by the mechanical philosophy of Descartes. Under this world view, the Earth is just a (soul-less) machine and man is distinct from nature and therefore entitled to dominate it; the Earth has no spiritual value. So this gives us license to dig up the planet to create the escalating distribution of products to global consumers and this is exactly what can be verified from the data. We refer to this as the business as usual trajectory. To correct this course trajectory, we propose two avenues: a) extend the concept and legality of the Public Trust Doctrine to all of Nature's resources so that current generations have an obligation to ensure the future generations can same similar access to these resources, b) adopt a systems thinking approach that prioritizes human equity, dignity, environmental justice and environmental health over escalating global GDP. In short, global justice should be our priority, not global profit. From the systems thinking viewpoint, the Earth is not a market commodity subject to resource exhaustion, it is rather a sacred equilibrium system for the welfare of all.
\end{abstract}

Keywords: Sustainability, Climate change, Systems thinking, Global consumption, Ocean 
heating

\section{Introduction}

We consider the coupled issues of a) increasing global consumption, b) accelerated climate change, and c) the need for the systems thinking approach to shift consumer values away from GDP based prosperity and towards the higher priority needs of human equity, dignity and overall environmental health. This move, often termed as "global justice", reflects earlier views articulated under the concept of 'just' sustainability (Agyeman et al., 2003) where social justice and global equity are the long-term goals of an evolving consumer world. Furthermore, we argue that the legal intent of the Public Trust Doctrine (PTD) (Sax, 1970) becomes consistent with 'just' sustainability when that doctrine is extended to include current resource availability for future generations. While the current PTD only includes protection of clean air and clean water for future generations, the spirit of that protection should be extended to include the basic right of all global citizens to have (equal) access to the Earth's natural resources to help sustain their culture. These resources include living with a "normal" regional climate and having access to various energy sources.

From the point of view of systems thinking, we argue the following: The Earth is a connected feedback system of which humans occupy but one channel. Yet the collective behavior of humans is to aggressively mine Earth's resources to support growing consumption. This aggressiveness has altered various natural cycles in the Earth and the emergent era of climate change and increasing weather volatility is the result. We have chosen to transcend various boundaries and in so doing we have potentially threatened the livelihood of not only future generations of humans, but virtually all other species on the planet. In this way, the last few generations have proved to be untrustworthy with respect to protecting the rights of future generations leading to the notion of Nature's Trust (Wood, 2014). Under this extended PTD (Blumm and Wood, 2015), the Earth is a system to protect, not to exploit. Living in harmony with nature represents the physical partnership between nature and all species and this endows the Earth with spiritual value. In this view, the Earth is a scared equilibrium system that promotes the welfare of all. Achieving future sustainability will require adhering to this mandate.

In this article we support this view using various data to define out our system is changing. We begin in Section 2 which shows how rapidly global consumerism is changing the planetary climate system. As measured by the consumption of consumer goods, we are now living at the most unsustainable time in history. In turn, this increase in global consumption is the fundamental drive of climate change via the energy associated with industrialization (as thermodynamic waste heat) and its eventual deposition into the oceans. We then show that the rate of ocean heating, the rate of annual $\mathrm{CO}_{2}$ emissions, and the rate of global temperature increase are all accelerating. This directly leads to a more volatile climate future. This escalation is a good signal that the Anthropocene (Steffen et al., 2007) is here and that humans are now a global geophysical force that can dictate how the Earth system behaves. The data essentially shows that we have proved untrustworthy as we are taking the Earth out of equilibrium on the short timescale by dumping too much energy into the oceans. 


\section{Macrothink}

In Section 3 we consider some of our historical motivations to consume the planet and consider policy implications that can help curb our behavior. In particular, we introduce the Mechanical Philosophy (Descartes, 1635; Merrill, 2008) as the means used by humans to declare themselves separate from nature and therefore entitled to harvest it. We then consider some of the policy implications that result from continuing this behavior into the future and consider the value of a systems thinking approach to better Earth management. In short, we need to be living in partnership with nature within ecosystem limits rather than dominating all of nature and ignoring those limits. Such a partnership views the Earth as the system which maintains our welfare and not as a market commodity to exhaust.

In Section 4 we present a connected discussion which convolves the data results with our overall behavior and further argue that our current priority system based largely on economic gain as the principal means to define prosperity, should be replaced where prosperity is re-defined in terms of fairness, environmental justice, dignity and global equity. Concluding remarks are presented in Section 5 and stress that adhering to the concept of Nature's trust requires a moral commitment to changing our current course of consuming Nature as fast as possible.

\section{The Data View: Global Consumerism Leads to Climate Change}

Our basic premise, well supported by the data, is that the outputs of human activity grow in a non-linear fashion with respect to the number of consumers. Here we use population growth as a proxy for consumers. This non-linear growth can be expressed as

$$
\text { Output } \alpha \text { (Population growth) }{ }^{\mathrm{N}} ; \mathrm{N}>1
$$

For linear change, $\mathrm{N}=1$. If $\mathrm{N}>1$ the increase in output is non-linear and we will refer to that as acceleration. We first apply this concept to some examples of resource usage and then move on to show that a) annual $\mathrm{CO}_{2}$ emissions are accelerating; b) global temperature increases are accelerating, c) consumption as measured by delivered consumer goods is accelerating and d) the rate of ocean heating is accelerating. We will primarily show this acceleration in graphical form as systematic departure from a linear trend and will derive the appropriate value for $\mathrm{N}$ in these cases.

\subsection{Resource Usage}

For an initial example, we consider the decadal growth of world steel production shown in Figure 1. We adopt the period 1980 to 2000 to define a linear baseline for growth (green arrow). Acceleration is then visually seen as later times have real world values that systematically live above the extrapolated linear trend. In the case of steel, production/consumption started to accelerate primarily due to the emerging global economic power of China, starting around 2003 (Vidal and Adam 2007). 


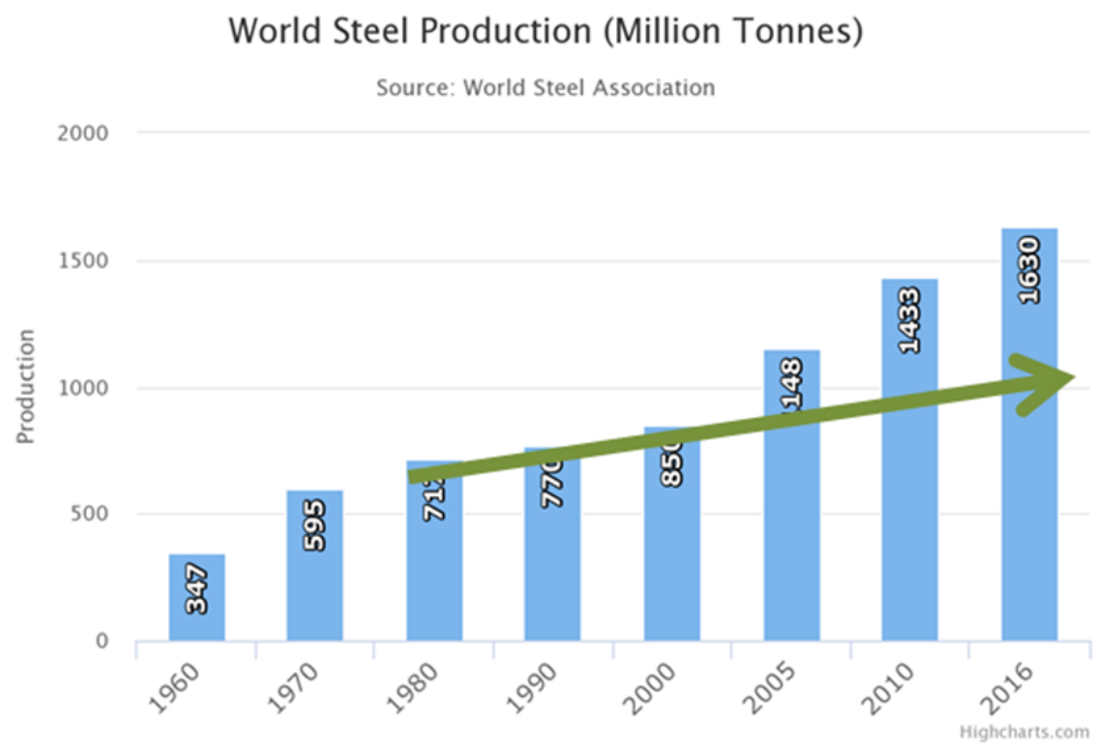

Figure 1. Decadal Production of World Steel: Green line shows extrapolation of linear trend defined by 1980-2000 time period

The value of $\mathrm{N}$ is arrived at as follows:

- $\quad$ over a span of 56 years steel production has increased by a factor of 4.7

- $\quad$ over this same time population growth has increased by a factor of 2.45 .

- $2.45^{\mathrm{N}}=4.7 ; \mathrm{N} \sim 1.75$

The meaning of $\mathrm{N}$ is that if the population doubles, the associated steel output does not also double but increases by $2^{1.75}=3.6$ times more steel. Most any resource usage conforms to this general non-linear dependence between number of consumers (proxy by population growth) and actual usage. Some other examples are:

- over the period of $1985-2015 \mathrm{~N}$ for soy production was 4.5 (doubling the population requires the production of 23 times more soy);

- over the period 1950 - $2015 \mathrm{~N}$ for fertilizer production was approximately 2;

- $\quad$ over the period $1970-2015 \mathrm{~N}$ for lithium production was approximately 3.6.

These accelerating resource usage rates a) are indicators that we are currently living in very unsustainable times which rapidly deplete remaining resources, b) "peak" resource is a likely part of our future - for instance Peak phosphorus (fertilizer) is likely to be around 2030 (Walan et al. 2014 ; Cordell and White, 2011) c) compromises the ability to deploy these resources in the future; for the case of lithium this strongly impacts future production of EVs [Jaffe, 2017 ; Speirs et al., 2014) ]. Values of $\mathrm{N}>1$ indicate increases in per capita consumption and this behavior depletes resources at an accelerating rate. For example, if moving towards a more sustainable means of energy production relies on the availability of certain raw materials (e.g. lithium for batteries, neodymium or dysprosium for magnetic 


\section{Macrothink}

motors on wind turbines, platinum for fuel cell catalysis, tellurium for more efficient solar PV panels) then, for $\mathrm{N}>1$, we run the risk of exhausting these materials before they can be deployed. This is another example of a violation of the PTD as future generations will not have access to these materials - they are gone.

\subsection{Climate Change}

We start by using the observed concentration of atmospheric $\mathrm{CO}_{2}$ (in units of ppm) as the input and the global annual mean temperature anomaly $(\Delta \mathrm{T})$ as the output to examine non-linear behavior. In figure 2 we plot the decadal average of annual $\mathrm{CO}_{2}$ emissions as measured at the Mauna Loa Observatory (http://scrippsco2.ucsd.edu/data/atmospheric_co2/) and show the maximum emission for a given year in that decade. For reference, the solid red line in Figure 2 is the average annual emission over the period 1960-2000 (1.34 ppm).

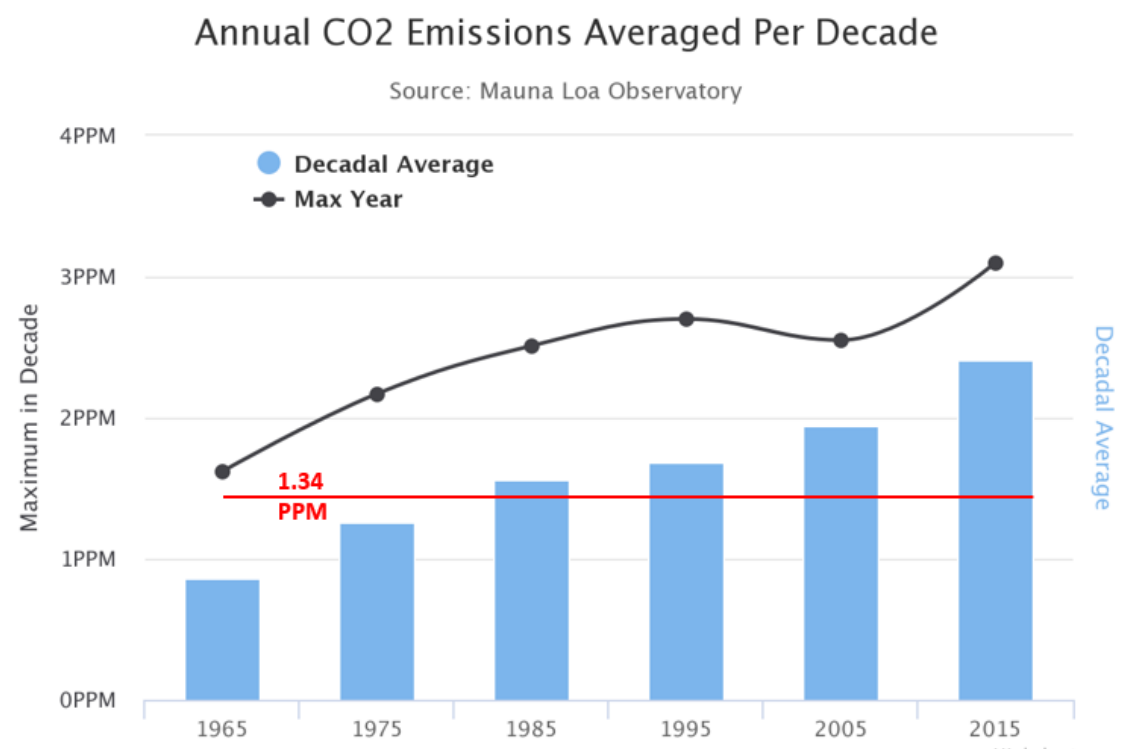

Figure 2. The growth rate of annual $\mathrm{CO}_{2}$ emissions, per decade, in units of ppm is shown in the blue columns. The black dots refer to the maximum emission year in a given decade.

Analysis of the Mauna Loa Data set shows:

- The current decadal annual increase in $\mathrm{CO}_{2}$ concentration is $2.41+/-0.38 \mathrm{ppm}$. This is almost twice as large as the $1.34+/-.36$ ppm value during the $1960-2000$ periods.

- For the current decade (2010), every single year has a larger annual emission than the long term 1960-2000 average of 1.34 ppm.

- For the previous 5 decades, the average annual emission rate is $1.46+/-0.42 \mathrm{ppm}$. This decade's current value of 2.41 is 2.26 standard deviations larger than the previous decadal value. This increase has only a $1.2 \%$ probability of randomly occurring and therefore statistically indicates systematically increasing annual $\mathrm{CO}_{2}$ emissions and a more rapid buildup of atmospheric $\mathrm{CO}_{2}$, i.e. acceleration.

- If we extrapolate this observed increasing annual rate out to 2030 then we will be adding an additional $30-35 \mathrm{ppm}$ reaching approximately $440 \mathrm{ppm}$ by then. This pace 


\section{Macrothink}

rapidly hinders the overall ability to achieve atmospheric $\mathrm{CO}_{2}$ level stabilization; in particular, stabilization at 450 ppm (e.g. Wigley, 2018) now seems impossible.

- For the data corresponding to the decade of the 1990s we have removed the anomalously low value for $\mathrm{CO}_{2}$ emissions in the year following the Mt. Pinatubo eruption. This volcanic explosion temporarily changed atmospheric chemistry such that $\mathrm{CO}_{2}$ mixes out at a faster rate, leading to some reduction in average atmospheric concentration (Frolicher et al., 2013 ; Robock, 2000 ; Stenchikov et al., 1998). With that anomalous period removed, we find that the variation around the value for each of the decades is similar, although somewhat higher in the decades of the 1980s and 1990s. Overall, this indicates that while we have not (yet) significantly changed the natural variations in the annual $\mathrm{CO}_{2}$ emissions cycle, we have changed the zero-point of that cycle through systematically increased addition of $\mathrm{CO}_{2}$ to the atmosphere. The near constancy of these variations is summarized in Table 1.

Table 1. Standard Deviations Per Decade for annual $\mathrm{CO}_{2}$ emissions

\begin{tabular}{|c|c|c|c|c|c|}
\hline $1960 \mathrm{~s}$ & $1970 \mathrm{~s}$ & $1980 \mathrm{~s}$ & $1990 \mathrm{~s}$ & $2000 \mathrm{~s}$ & $2010 \mathrm{~s}$ \\
\hline $0.34 \mathrm{ppm}$ & $0.43 \mathrm{ppm}$ & $0.52 \mathrm{ppm}$ & $0.58 \mathrm{ppm}$ & $0.40 \mathrm{ppm}$ & $0.38 \mathrm{ppm}$ \\
\hline
\end{tabular}

To assess the change in average surface temperature we make use of the most recent data on global land+sea temperature anomalies as provided by NASA Goddard (https://data.giss.nasa.gov/gistemp/). The use of both land and ocean is a far more sensible approach than just using land-based data. For instance, urbanization effects over the period of record are not likely to influence ocean-based temperatures compared to the land temperatures. By NASA convention, the measured temperature anomaly $(\Delta \mathrm{T})$ for a given year uses a baseline of 1951-1980. These data are plotted in Figure 3 where again we show that a linear extension (green line) based on the previous rise of $\Delta \mathrm{T}$ starting in 1980 does not predict the observed change seen over the last 3 years (2015, 2016 and 2017; 2015/2016 both set successive world records). As further argued in Bothun and Chess (2017), this acceleration revealed by the most recent data strongly suggests the need for more aggressive climate change policy. This acceleration is now likely responsible for some recent catastrophic large-scale weather-related events (such as Hurricane Harvey, the California Wildfires). Indeed, 2017 set a new record for insured financial losses related to Natural Disasters (Tabuchi, 2018). 


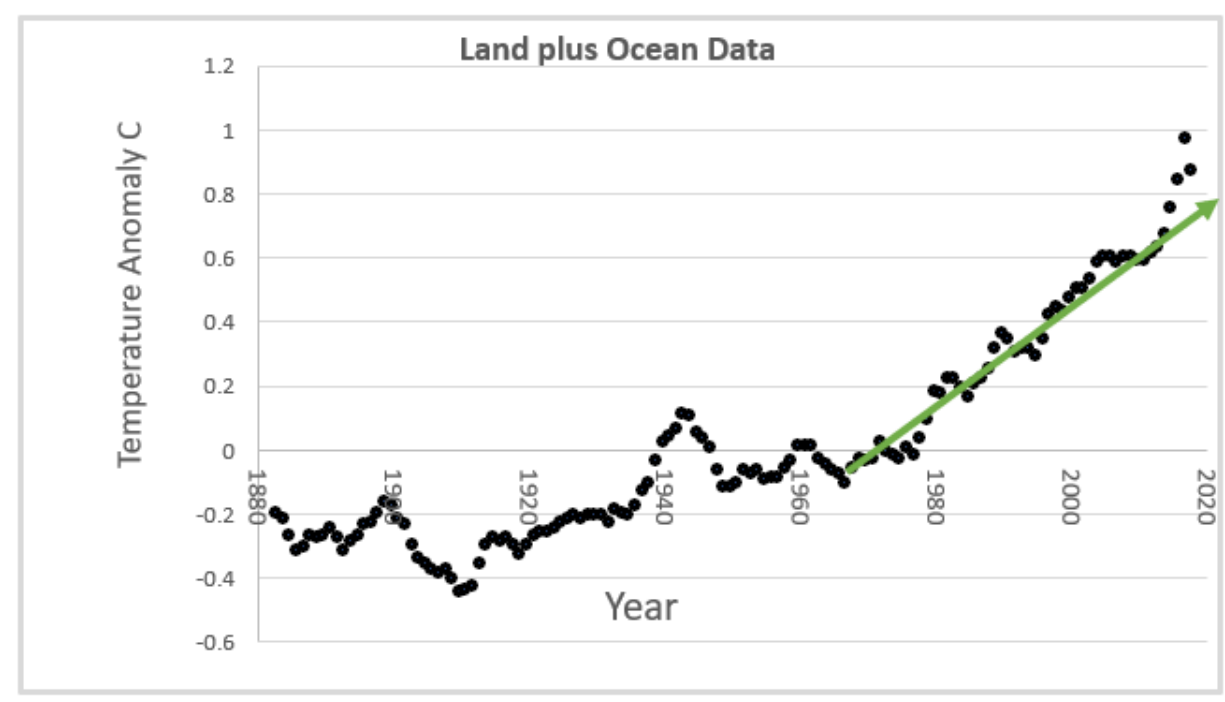

Figure 3. NASA Goddard annual data from 1880-2017; Data is averaged over every 5 years. The green line is linear fit to the 1980-2014 time period; the last 3 years of data departs from this linear trend, indicating acceleration.

\subsection{The Rise of Global Consumerism}

For the most part, consumer goods are shipped via containers on large container ships. These containers are known as TEUs (20-foot equivalent units). These ships disembark at about 25 major container ports around the world from which the goods are distributed via road, rail or plane. The total energy associated with this process is large and consists of a) the energy associated with extracting the raw resources, b) the energy associated with converting raw resources in to consumer products and c) the integrated transportation of these goods. We refer to this as the embodied energy associated with the need to maintain our consumptive habits. Remarkably, the global industry has been able to keep up with consumer demand simply by building larger container ships and larger container ports. This is immediately seen in Figure 4 that shows a 10 year ramp up period (2004-2013) for the combined top 10 container handling points in the world (6 are in China, the remaining are in Singapore, Hong Kong, South Korea, and the United Arab Emirates; the largest US port at Los Angeles is rated number 18 and handles 4 times less volume than the world's largest port at Shanghai). In addition, we show the time evolution of the two top ports themselves. Note that as of 2013, some ports were handling 30 million containers which are about the same as the number of seconds in a year - 1 TEU per second is now being processed. 


\section{Container Traffic}

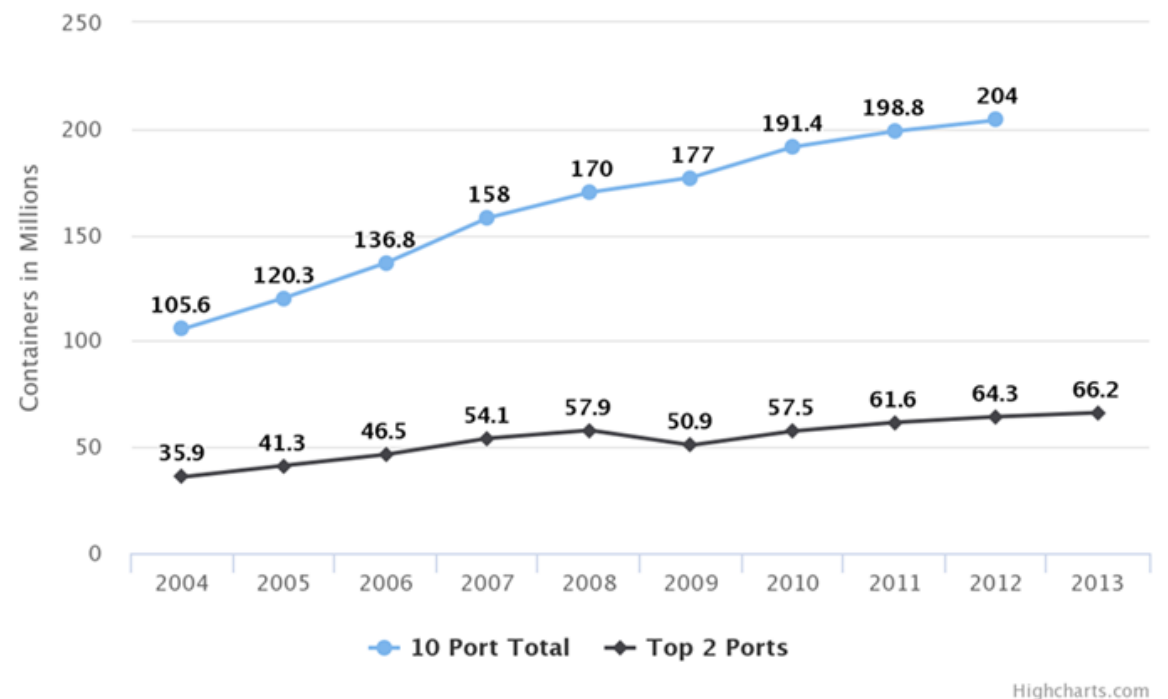

Figure 4. Time behavior of container traffic for the World's 10 busiest ports (blue line) and the World's two busiest ports, both located in China.

From 2004 to 2012 the top 10 ports expanded to double their capacity and over that time world population growth grew by about $10 \%$; this yields $\mathrm{N} \sim 7.3$ !

Next, we consider the tremendous increase in total container traffic volume. Figure 5 shows the data together with a $10 \%$ growth curve fitted to the 1990-2008 data. The economic meltdown of 2009 put a temporary halt to this enormous growth curve but the data show a rapid rebound and continued growth now at the level of about $5.5 \%$ per year.

Growth of Container Traffic 1970-2017 (est)

Drewery Shipping Consultants

$960 \mathrm{mTeu}$ 1000 mTEU

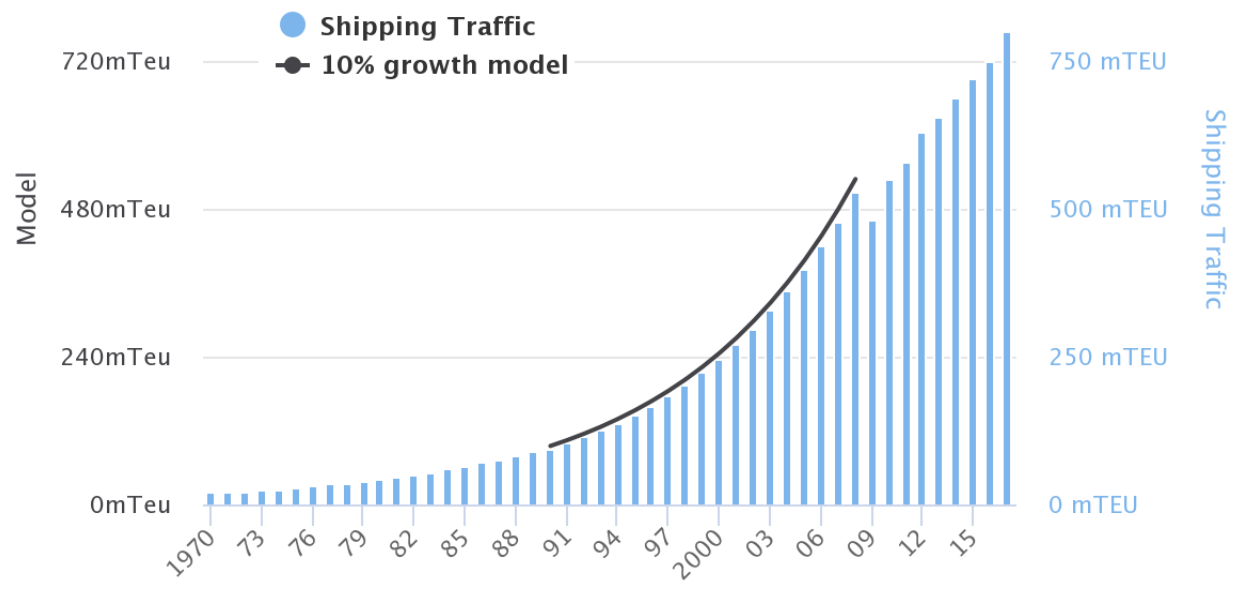

Figure 5. The growth of global shipping container traffic. Solid black line is a $10 \%$ growth curve applied from 1991 to just before the economic recession of 2009. 


\section{Macrothink

For the period of 1990-2008 the overall scaling is the following:

- World population grew by $28 \%(1.28)$

- Total container traffic grew by a factor of 6.5

- $\quad \mathrm{N} \sim 7.5$

For that absurdly high value of $\mathrm{N}$ if the world doubled its population it would use $2^{7.5}$ or 180 times more resources. Clearly the Earth is not big enough to satisfy this demand which has led to the notion of accelerating global ecological debt (Warlenius et al., 2015), further discussed in Section 4.

Finally, in figure 6 we show the evolution of the container ship itself. Over the last 50 years, the individual capacity of a container ship has grown by approximately a factor of 15 . In turn significant growth in container port facilities must also occur to handle this increased discharge of goods

\section{Evolution of Biggest Container Ships}

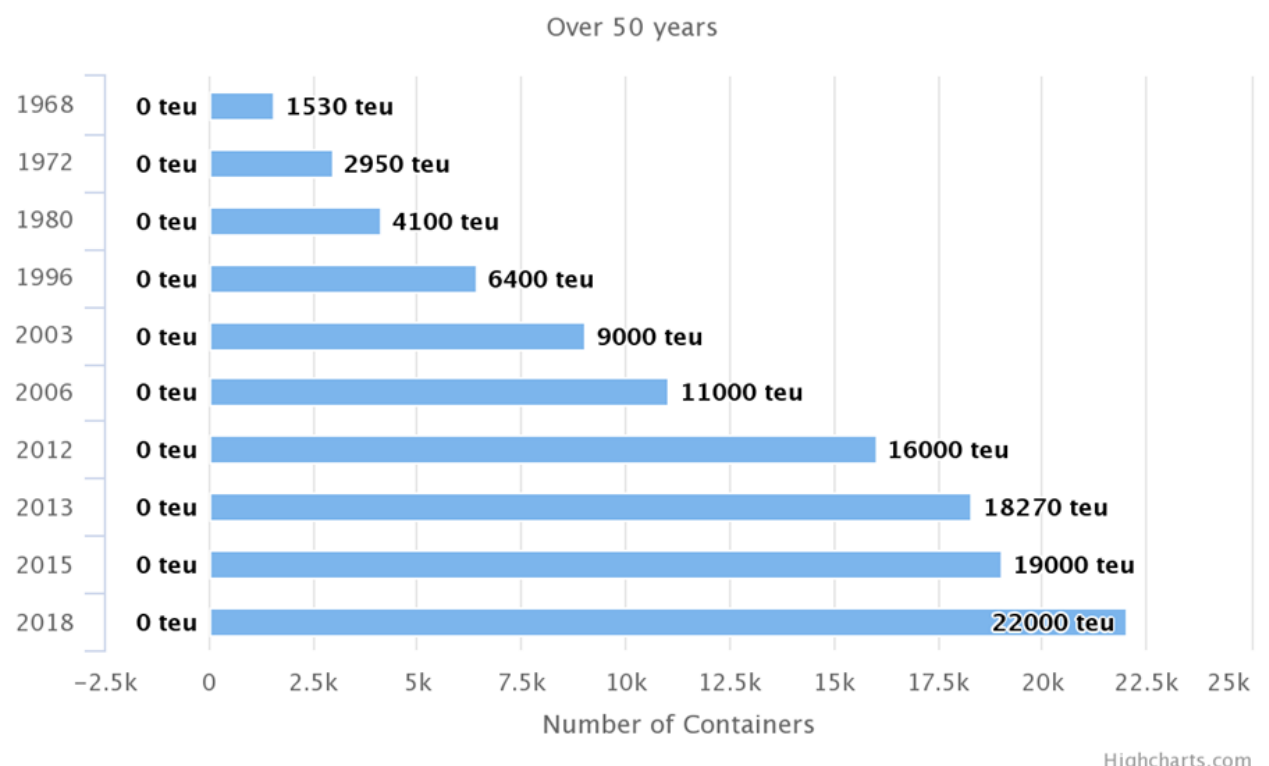

Figure 6. The evolution of the TEU capacity of individual container ships. Those ships that have more than 18,000 TEUs are not able to navigate through the Panama Canal.

Using the data for container traffic we can now show how the observed $\mathrm{CO}_{2}$ levels in the atmosphere respond to increases in container traffic. Due to lags in the system, there is never a one to one correspondence between our emissions activity on the Earth and atmospheric response; hence the $\mathrm{CO}_{2}$ content of our atmosphere did not suddenly see a reduction in 2009, even though that year saw a planetary wide reduction in greenhouse gas emissions of about $10 \%$. Figure 7 shows the relation between increased container traffic and increasing $\mathrm{CO}_{2}$ emissions, as averaged over 5-year periods starting in 1970. Although variations exist, over the long term a clear positively correlated trend has emerged. The fitted exponential curve provides an adequate description of this relation which can be then extrapolated for future 


\section{Macrothink}

predictions. For instance, the 2015-2020 periods will see an increase of about 215 TEUs of container traffic compared to 2010-2015 and a corresponding increase of about $14 \mathrm{ppm}$ of $\mathrm{CO} 2$ emission compared to the previous 5 years, thus taking us to about $420 \mathrm{ppm}$ by the end of the current decade.

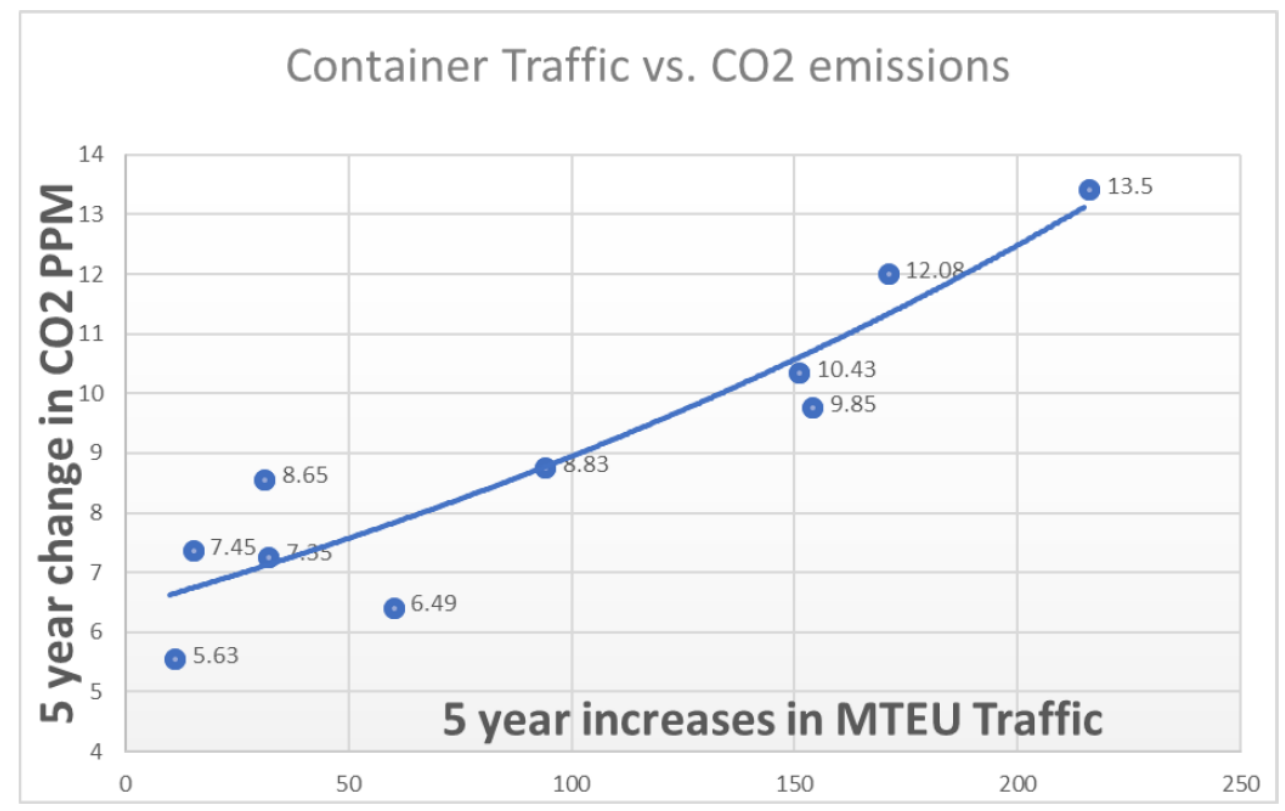

Figure 7. Positive relation between increases in container traffic (X-axis) and increases in $\mathrm{CO}_{2}$ emission (Y-Axis) as also given by the plotted data values. For example, a container increase of 100 million TEUS (an MTEU) corresponds to an increase in $\mathrm{CO}_{2}$ emission of about 9 ppm.

\subsection{Ocean Heating}

At its fundamental level, global climate change is driven by Earth's energy imbalance. Approximately $90-94 \%$ of this energy imbalance is stored as ocean heat content (OHC) (see Trenberth et al., 2014; Dahlman, 2015). Even though thermodynamic waste heat originally is dissipated in the atmosphere, the collective action of precipitation washes that heat out, storing in temporarily in the soil and ground water before eventually ending up it is final repository - the Earth's oceans. Therefore, we have the simple expectation that the total embodied energy associated with increasing industrialization/consumption will systematically raise $\mathrm{OHC}$. The systematic increase of $\mathrm{OHC}$ has now been well documented (e.g. Levitus et al., 2000; Levitus et al., 2012). Ocean buoy measurements of temperatures at various depths in combination with surface meteorological measurements can be used to extract sensible heat content in that region of the ocean (see Yu et al., 2004).

While various calibration issues involving the difference between permanent buoys and those on ships exist, those seem to have been sorted out (Cheng et al., 2017) and we now have a well calibrated data set revealing the behavior of $\mathrm{OHC}$ over time. The most recent data (from https://www.nodc.noaa.gov/OC5/3M_HEAT_CONTENT/basin_data.html) is plotted in Figure 8 where the values for OHC (Y-axis) are determined from the 1997-2005 baseline. 


\section{Macrothink}

The data are averaged over every 5 years to help reduce some of the intrinsic variability. The mere fact that $\mathrm{OHC}$ is increasing with time means that more heat is now added to the ocean per year than it can dissipate through natural methods.

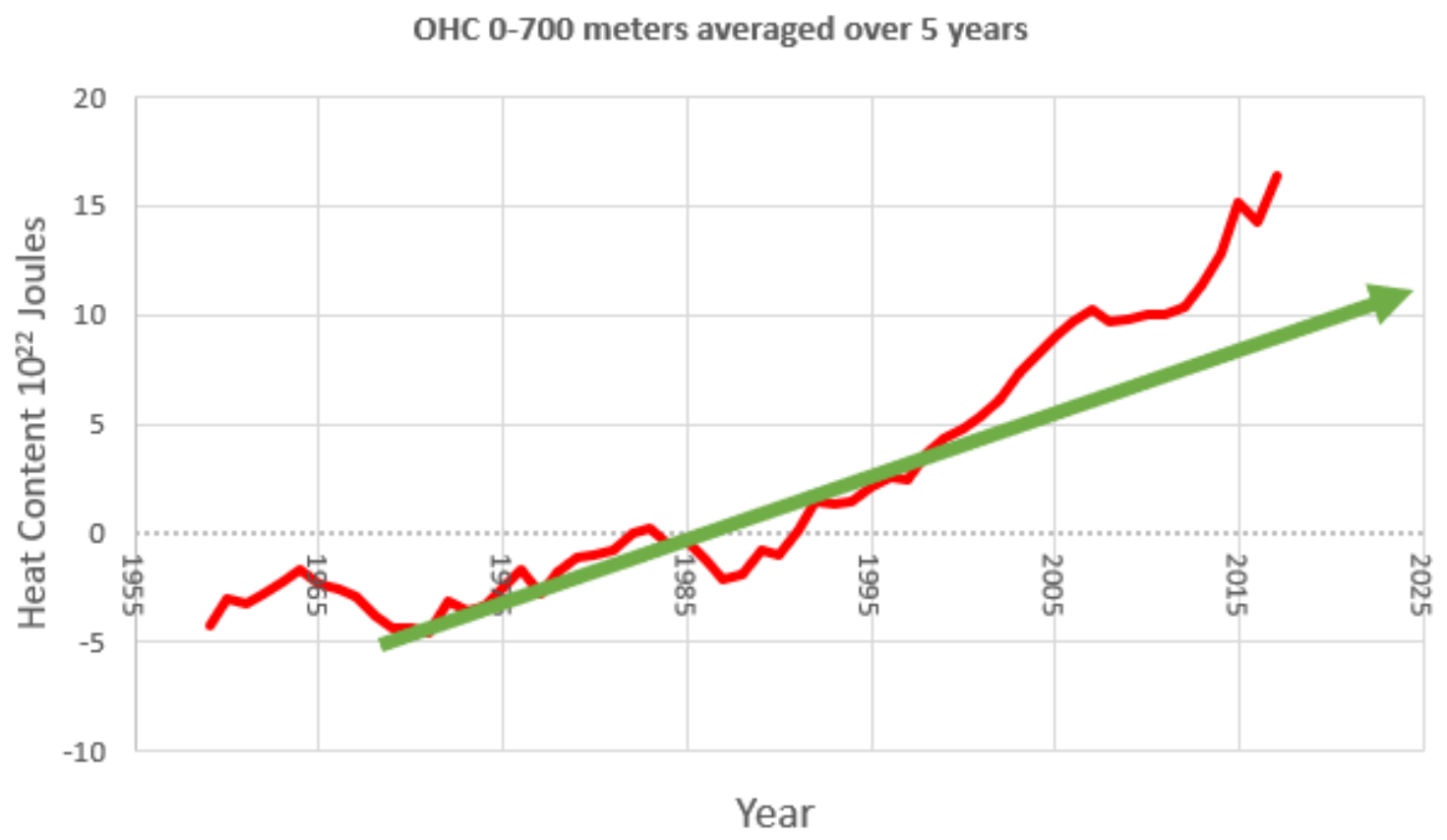

Figure 8 . OHC data for the $0-700 \mathrm{~m}$ layer at the surface of the ocean. The green line is a linear baseline from the time period 1970-2000.

Figure 8 informs us as follows:

a) The rise in ocean heating over period 1970 to 2000 is linearly represented (green arrow) in a reasonable manner. Over the last 15 years, however, the rise in OHC is systematically departing from the extrapolation of this linear trend baseline, again indicating acceleration. More specifically, the linear trend from 1960-1991 is $0.15+/-0.08 \times 10^{22} \mathrm{~J} / \mathrm{year}$ while from 1991-2015 it is $0.61+/-0.04 \times 10^{22} \mathrm{~J} /$ year, almost 4 times larger. The lower error in the latter time period reflect the presence of more and better sensor measurements over the world's oceans. Starting around 2010, the data indicate a significant upturn in the rate as that time period has a slope of $\sim 1.05+/-0.05 \times 10^{22} \mathrm{~J} / \mathrm{year}$. This rate is alarming as it 7 times higher than the 1960-1991 rate.

b) The most important channel for removing excess surface heat from the oceans is deep sea transport (Bryden \& Imawaki, 2001 ; Hoffert et al. 1980) but this mixing operates over a few hundred years timescale (Hansen et al., 1985). Now the oceans have experienced reduced efficiency in terms of handling waste heat input and are clearly retaining more heat.

We stress here that the Y-axis in Figure 8 is not temperature - instead ocean surface buoy measurements of temperature have been converted to heat content. Over the last 5 years we have added $\sim 5 \times 10^{22}$ Joules of energy to the world's oceans. These units are likely meaningless to most readers but their rough equivalency is as follows: 
- The instantaneous release of 350,000 hydrogen bombs

- Each person on the planet using 175 gallons of gasoline per day

- 8 trillion annual barrels of crude oil (current world consumption is 0.04 trillion)

- Each person on the planet using $1 / 2$ a billion AA batteries per year

The above numbers represent the sheer nonsensical scale of global consumerism and the resulting extra energy that is delivered to the system. In turn, this inevitably changes the horizontal (ocean currents) and vertical temperature distributions within the oceans and this directly drives jet stream patterns which determine regional weather (Huber \& Sloan, 2000 ; Griese \& Polvani, 2014 ; Blackport \& Kushner, 2017) Simply put, the coupled ocean-atmospheric system has more energy to work with it, due to our industrial actions over the last 100-150 years. The inevitable consequence of increases in $\mathrm{OHC}$ is to change the weather and climate pattern on the Earth.

\section{Implications of Our Actions}

In the previous section we have used to data as the lens to examine the collective behavior of humanity which is to process Earth resources, as fast as possible, and churn those resources into consumer products, which we are now consuming at an accelerating rate. The embodied energy associated with this processing is not a natural system of the Earth and therefore represents an additional source which cause a temporary energy imbalance in the system. That added energy directly manifests as increased $\mathrm{OHC}$ and subsequent climate change leading to a more volatile weather system. From the physical point of view, humans are in a necessary partnership with nature. The existence of this energy imbalance in the system means that humans have now put the system into a new state, precisely because they have not acted like this necessary partnership even exists.

\subsection{Historical Considerations}

Despite boundary conditions implied by the nature of partnership, many human cultures have historically pursued dominance over the Earth's resources as their operational philosophy. Until the invention of the steam engine, that operational philosophy had only local impact on small scales. But how does such an operational philosophy come about? Indeed, where do humans get the very notion that they are not part of nature? Here we greatly simplify history and assert that this ethos becomes operational with the rise of the Mechanical Philosophy, primarily through the thinking and writing of Descartes (1635). Under this world view, the Earth is nothing more than a (soul-less) machine - it has no spiritual value and no sacred value. Furthermore, it becomes established that man is distinct from nature and therefore entitled to dominant it. As Descartes often espouses,

....and thus render ourselves the lords and possessors of nature (see also Merrill, 2008).

This Mechanical view of the world is firmly in place before the industrialized revolution so that sustainable harvesting of Earth resources is never part of our value system. The invention of the steam engine launches the industrialized era that be to eventually take the Earth system 
out of equilibrium; slowly at first, but rapidly escalating in the post-World War II consumer world (Freidman, 1985). This mechanical philosophy mode of digging up the planet as fast as possible and churning the crank for the escalating global distribution of consumer products is completely opposite of the physical manner in which the Earth system operates (Durning, 1992). Our real-world behavior strongly suggests that we still live in the mechanical philosophy system. In that system, nature has no intrinsic value but serves humans only as a resource.

The damaging nature of this value system was recognized earlier in the 1930s by the social critic Lewis Mumford as articulated by these relevant quotes:

(The processes are) doubly ruinous: they impoverish the earth by hastily removing, for the benefit of a few generations, the common resources which, once expended and dissipated, can never be restored (Mumford, 1928)

The vast material displacements the machine has made in our physical environment are perhaps in the long run less important than its spiritual contributions to our culture. (Mumford, 1930a)

...the bourgeois culture which dominates the Western World is founded... on the principle of conspicuous waste. (Mumford, 1930b)

In addition, Mumford was one of the first policy champions of using renewable energy to substitute for fossil fuels - more specifically to use hydro power to generate electricity instead of Coal. In various writings (Mumford 1934, 1938) described coal as serving as the engine of the industrial revolution's "upthurst into barbarism". He described the production of coal as a thing that produced "a befouled and disorderly environment" and described coal mining as a process that "wrenched coal from the Earth requiring the simultaneous exploitation of labor and nature" (Needham, 2014). In perhaps an early vision of the PTD, Mumford states that "with hydro -electricity, the clear sky and clean waters would come back again" and would finally bury the "maggoty corpse" of the Coal era. Alas, the corpse is still rather far from being buried, since, as of May 2018 renewable energy sources stand as only $8.5 \%$ of the total world energy production (https://oilprice.com/free-widgets). Hence, we largely remain on the course of action that produces a befouled and disorderly environment.

Global consumerism was first born in the USA as post World War II escalating consumer spending was regarded as the best way for the USA to retool its War Time economy toward higher manufacturing to become the dominant economic world power as quickly as possible (Nelson and Wright, 1992 ; Maier, 1977 ; David and Wright, 1997). Two important quotes from this period are illustrative of this approach and its effect on American consumer culture and the subsequent throw-away society (Whitley, 1987).

Only if we have large demands can we expect large production. Ever-increasing consumption on the part of our people is one of the prim requisites for prosperity. Mass consumption is essential to the success of a system of mass production - (Nathan 1944)

Our enormously productive economy demands that we make consumption our way of life, 
that we convert the buying and use of goods into rituals, that we seek our spiritual satisfaction and our ego satisfaction in consumption. We want things consumed, burned up, worn out, replaced and discarded at an ever-increasing rate. - (Lebow 1955)

This consumer mind set convolved with making America an economic power meant getting goods to market as fast as possible. This mantra has now carried over to a global context, with China now dominating the goods to market infrastructure (Wang et al., 2016). Hence, to date, we have shown no ability to deviate from our incessant use of the Earth, acting exactly like lords and masters over its resources.

\subsection{Some Policy Implications}

In guiding future policy to facilitate a move towards sustainability and sustainable development, the most relevant lens may be that of global equity/global justice. An early vision of this can be found in the 1987 Brundtland Report Our Common Future which states,

"... development that meets the needs of the present without compromising the ability of future generations to meet their own needs,"

These sentiments were then followed up in the 1996 World Commission on Environment and Development report which states:

The environment must be protected ... to preserve essential ecosystem functions and to provide the wellbeing of future generations; environmental and economic policy must be integrated; the goal of policy should be an improvement in the overall quality of life, not just income growth; poverty must be ended and resources distributed more equally; and all sections of society must be involved in decision making.

Both of these ideas embody the notion of the PTD and its extension to all of Nature.

There are two key concepts in these early reports: 1) resources distributed more equally - this seems to be a vital need for achieving sustainability, and 2) the overall quality of life should supersede mere income growth. With respect to point 1, data indicate that we are increasingly moving away from resource equity. For example, the 2008 World Bank report showed that for 2005, the world share of consumption can be broken down as follows:

- $75.6 \%$ is consumed by the Worlds' richest $20 \%$

- $21.9 \%$ is consumed by the middle $60 \%$

- $1.5 \%$ is consumed by the world's poorest $29 \%$

An update to this situation is available from the 2013 Oxfam International Report which claims we are moving toward a rather absurd situation in which the richest $1 \%$ of the world will own more than $50 \%$ of the world's wealth by the year 2016 (it will take some years to verify if this came true). The scale of inequality is thus staggering and every year the gap between the $1 \%$ and the rest widens. A useful visual representation of the data in the Oxfam report is shown in Figure 9 where the land area of the world is converted to wealth -- the bottom $50 \%$ (red) of the world owns only an area of the size of Mongolia; the middle $40 \%$ 


\section{Macrothink}

(blue) owns most of the former Soviet Union; the remaining 10\% (gold - naturally) owns all the rest.

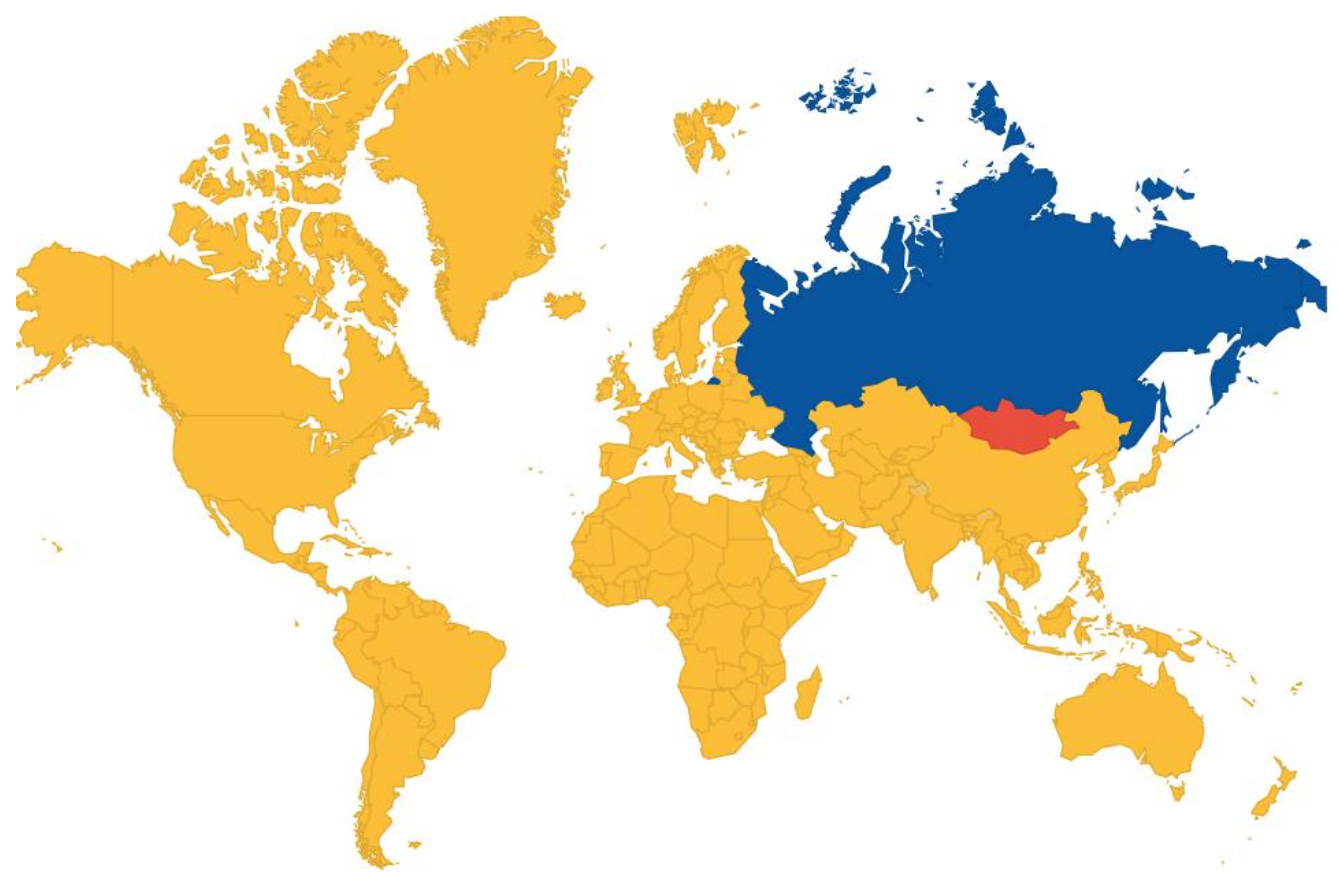

Figure 9. Converting wealth inequity into equivalent land area proportions on the surface of the Earth

The second point is that the quality of life has more importance than income growth. As long as the personal perception of prosperity is related solely to income issues, which ultimately drive consumption, then no move to sustainability seems possible. But, sustainability is not about the more efficient harvesting of resources, it's about establishing a more equilibrium use of resources with respect to the innate planetary cycles. This is well articulated here:

'Sustainability cannot be simply a 'green', or 'environmental' concern, important though 'environmental' aspects of sustainability are. A truly sustainable society is one where wider questions of social needs and welfare, and economic opportunity are integrally related to environmental limits imposed by supporting ecosystems" (Agyeman et al., 2002).

"The need to ensure a better quality of life for all, now and into the future, in a just and equitable manner, whilst living within the limits of supporting ecosystems" (Agyeman, 2005).

Furthermore, this process of continually defining social needs by consumption leads directly to a kind of social inequality that ultimately does significant damage to various social structures (Wilkinson and Pickett, 2009). One of the frameworks for a just sustainability is then to replace consumption based social identity with a more meaningful grounding in global justice and environmental welfare (Schlosberg, 1999). The transition to such a replacement requires the systems thinking approach in which humans are bound to live within the resources provided by Nature. 


\section{Ml Macrothink}

Environmental Management and Sustainable Development

ISSN 2164-7682 2018, Vol. 7, No. 3

\subsection{Systems Thinking and the Recovery of the Sacred}

The systems thinking approach involves making decisions and policies within the conceptual and quantitative framework of an interconnected system with robust feedbacks. Physically, the Earth is a large connected feedback system of which human activity is but one channel in the overall cycle. All cycles are characterized by two things a) material exchange rates between various reservoirs and $b$ ) the existence of buffers in the system that can store material/energy over some timescale. In this way, a system can be out of equilibrium on either short spatial or temporal timescales, but on average equilibrium is always maintained. Human dominance over Earth resources disrupts energy pathway exchange rates and modifies buffers (e.g. paving over a wetland). These actions keep us out of equilibrium. This is well described in the Living Planet Report (http://awsassets.panda.org/downloads/lpr_living_planet_report_2016.pdf) which has consistently plotted our global "ecological debt" - which is the number of Earth's that would be needed to instantaneously support our annual consumption. Because there are buffers in the system (we don't use all the available crude oil in a single year because a lot of it is still stored) overshoot of equilibrium is a natural occurrence. This has given rise to the term Earth Overshoot Day which indicates the day of a particular year in which we have used up an Earth's worth of resources to support our annual consumption for that year. Figure 10 shows that we are reaching this day earlier and earlier. Notice also the relative sharp decrease between 2005 and 2010 compare to other similar time periods. In 2017, the overshoot day was August 5 or day 217. Since that is approximately $60 \%$ of the year, then for the full year of 2017 we used1/.6 Earth Masses to support that year's consumption. This is perhaps the best indicator that we are out of equilibrium and have been for some time as we first passed one Earth mass in 1987.

\section{Imabalance between resource use and annual renewal of that resource}

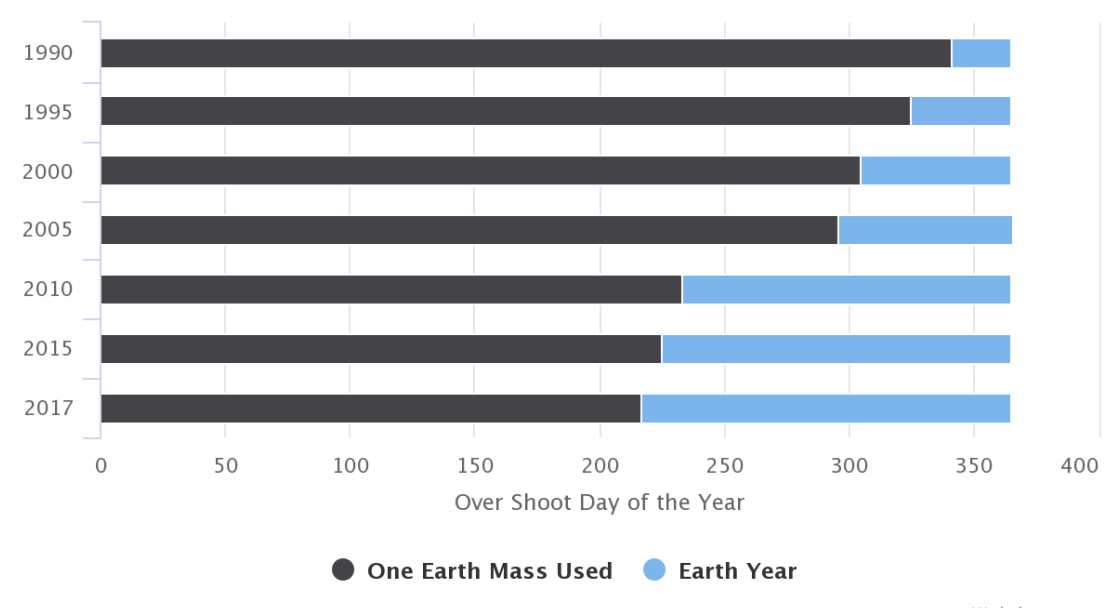

Figure 10. Evolution of Earth Overshoot Day. As time goes on we use up one Earth mass of resources earlier and earlier in the calendar year. Data comes from the Global Footprint network (http://www.dw.com/en/earth-overshoot-day-living-beyond-our-means/a-19444507) 
As an example of living within a system using systems thinking, let's consider two cultures (Bothun, 2017): culture D (for dominance) and culture S (for sustainability or S for sacred the two might be the same) and their treatment of an energy resource in the context of planetary subjugation and climate change. Our continued reliance on mined resources as the principle source of electricity and energy generation carries with it a tremendous environmental cost as well articulating a consistently inappropriate message that we exist to dominate the planet. This behavior is fully consistent with the value system of Culture D; digging up resources represents dominance on the part of the digger and the Mechanical Philosophy gives entitlement to that digger. Harmony with nature is completely absent. In stark contrast is the both symbolic and physically real harmony of a spinning wind turbine that produces electricity by natural air movement. In this case, we only get electricity when the wind is blowing and therefore are in a necessary partnership with nature for the use of that resource (e.g. culture $S$ ). Such a partnership tends to foster better resource management as well as having a culture which recognizes and conforms to environmental limits - you only get to use electricity with Nature gives you the ambient energy for conversion. Using machines to dig holes in the ground from a seemingly infinite resource, unbinds us from any notion of partnership and allows resource consumption to steadily increase, which has clearly played out in the real world. In this way culture D can never honor the PTD but culture $S$ is bound by it. Culture $\mathrm{S}$ is clearly practicing systems thinking and is living within the natural limits of that system, one of the principals espoused by the idea of "just" sustainability.

Hence, a proper integration of systems thinking into the way we behave means that issues of fairness, environmental justice, dignity and global equity become more important than what should become the obsolete notion that increased human prosperity only comes from increased consumption and the associated conquered resources. While the concept of environmental justice is complex and nuanced (Sen, 2009; Schlosberg and Collins, 2014) it does seem to distill to one reality - the Earth's climate and energy resources should be equally available to all its citizens. No improved technology with more efficient resource extraction will overcome the basic problem that our current value system is skewed too much towards economic growth and too little toward the more fundamental values of environmental justice, social justice, equity and dignity for all the citizens of the Earth. Clearly, we must collectively regain the notion that the Earth is sacred and we need to respect its boundaries, not conquer them. Systems' thinking informs us that we can never rise above the system and that we should always make decisions that support the health of that system. Indeed, there is strong evidence that indigenous cultures organized their entire way of life around systems thinking, largely because of holding a sacred view of Nature (Barnhardt 2005, ; Breildlid 2009). Rediscovering this world view is likely the most promising way to curb our short-term consumption addiction so as to better maintain the system for future beings, exactly what Nature's trust demands.

\section{Discussion}

Using available data, we have set a framework for how accelerated global consumption and its associated embodied energy, necessarily leads to escalating $\mathrm{OCH}$ and the subsequent acceleration of climate change. The combined waste heat of all the industrial processes 
associated with keeping us on the business as usual trajectory (e.g. Figure 5) is the root driver of climate change. As we continue to escalate global consumption, the rates of impact on the natural system will correspondingly increase. This leads to an increase in the frequency of extreme weather events which is now borne out by the data (Mann et al., 2017; Demski et al., 2017; Lesk et al., 2016; Stott, 2016; Tang et al., 2014). At the moment, most of these extreme events are related to large scale flooding, particularly in Europe (Madsen et al., 2014). In addition, accelerated OHC leads to an accelerated melting of Arctic sea ice (Stroeve et al., 2014) which, if gone, will change the energy balance of the Earth by lowering its Albedo 15\% (Pistone et al., 2014). Our collective dominance of nature has fundamentally changed the energy balance of the Earth. Who say's we are allowed to do this?

We have introduced the idea of systems thinking as a value system than can help bring forth the principles of "just" sustainability. We have cited previous examples which argued that policy needs to move away from economic priority and towards ensuring a healthy planetary ecosystem, for the benefit of now and future generations. In this way we can help to ensure the health of the system that supports all species, instead of changing the very system that we live in. Cronon (1996) demonstrates the systems thinking approach in the essay "The Trouble with Wilderness". He asserts that the system of wilderness is "everywhere" and not just in protected and isolated places. That is, a system is pervasive and not just a collection of isolated components. An isolated National Park that preserves the Wilderness is just that, an isolated component. But system behavior is defined by the way in which all the components interact - there is no isolation and hence we should have a mindset that wilderness is indeed, everywhere. The idea of wilderness everywhere should remind us of our partnership with nature and the various environmental limits that exist in the system. Yet we are clearly not living within our environmental limits and are actively transcending them. Examples abound that our on the ground behavior is still very much related to conquering nature: blowing the tops off of Appalachian Mountains to mine coal; drilling for possible oil located under 5000 feet of water and 15,000 feet of marine sediments (e.g. Deep Water Horizon). These are acts of desperation to maintain BAU. Our demonstrable inability to consume within our global resource limitations clearly shows, as Descartes originally argued, that the Earth is essentially a machine that offers us resources that we can just use up.

We have also introduced the Public Trust Doctrine (PTD) and its possible extension to Nature's trust as judicial examples of generational accountability. The spirit of the PTD implies that all generations (perhaps all species) should enjoy the right of living in the same equilibrium system enjoyed by previous generations. If we are indeed to honor Nature's Trust we can do so in two ways: a) extended the legal nature of the PTD so that a judicial system decides how to best protect the environment (Wood, 2014) or b) through systems thinking; humans must realize that they have a moral obligation to honor Nature as a sacred system that benefits all creatures. This treatment of the Earth as merely a market commodity should no longer be tolerated. Human actions have taken our sacred equilibrium system most definitely out of equilibrium and this threatens the right of future generations to access various Earth resources in the manner we currently do. This is one of the major challenges for the more developed countries of the world - how to enlighten their citizens that the drive for steady 
personal income growth is now less important than considerations which raise the probability of a more livable world for future generations. How can these current generations due a better job of honoring Nature's Trust than the previous generations?

We have also shown that the general output of human activities has non-linear scaling with respect to the growth of consumers. If the perception of the lay public as well as policy makers is that growth is mostly linear (e.g. $\mathrm{N}=1$ ), then in the real world of accelerating changes, each passing year puts us farther behind our ability to mitigate or adapt to a growing problem (Bothun and Chess 2017). Yet we ignore this and continue consumption at these accelerated rates. Amazingly, the world has been able to build infrastructure that has allowed this escalation of consumption on the global level. This also maintains our BAU trajectory let's do more, faster and ignore the consequences to the system. A good example of consequence is the country of Bangladesh. In 1998, Bangladesh had a preview of their likely dismal future as they experienced a severe monsoonal flood, which inundated about $50 \%$ of the land area that had very long-term impacts on basic nutrition (del Ninno and Lundberg, 2005). As perhaps the best example of a violation of some global PTD, at some point in the near future most of Bangladesh will be flooded due to rising sea level, storm surge, and catastrophic monsoonal moisture (Thiele-Eich et al., 2015). In essence, the homeland of some 150-200 million people will be lost as a direct result of continued usage of fossil-based energy to accelerate global consumption. For those citizens the world has proved to be completely untrustworthy.

\section{Conclusions}

The Mechanical philosophy mode of digging up the planet as fast as possible and churning the crank for the escalating global distribution of consumer products is completely opposite of both the systems thinking approach and the physical manner in which the Earth system operates. Escalating consumption is likely maintained under the continuing belief that prosperity is best measured by economic means only. Indeed, the 2009 global economic meltdown caused a (slightly) reduced rate of global consumption but we rapidly got back on the BAU trajectory. This directly shows that globally, we seem unable to change our behavior. Accelerated climate change and its associated increasing weather volatility is the direct system response to our consumer actions. Indeed, how can we expect there to be no significant outcomes from this action and has not this change of the system been a clear violation of the PTD?

A rather ancient view of the world, held by many indigenous cultures, clearly rests on the idea that the Earth is a system that humans are in partnership with. In that view, it is irresponsible for the humans to significantly alter the system. Rediscovering this world view is likely the most promising way to curb our short-term consumption addiction so as to better maintain the system for future beings. It really is incumbent on us to shift our priorities. The concept of the PTD and Natures trust would argue that escalating use of planetary resources to promote "ever-increasing" consumption is a danger to not only future children, but millions of other species. It is our moral (and perhaps future legal) duty to preserve the system and to honor the trust mandate. It's one Earth, one tiny vessel that has sustained all 


\section{Macrothink}

Environmental Management and Sustainable Development

ISSN 2164-7682 2018, Vol. 7, No. 3

forms of life over the last 4 billion years - who the hell are we to disrupt that?

\section{Acknowledgement}

I would like to thank Roberta Mann, University of Oregon Law School, for stimulating discussions regarding the idea of extending the Public Trust Doctrine to include more environmental areas.

\section{References}

Agyeman, J., Bullard, R. D., \& Evans, B. (2002). Exploring the Nexus: Bringing Together Sustainability. Environmental Justice and Equity, Space and Polity, 6(1), 77-90.

https://doi.org/10.1080/13562570220137907

Agyeman, J., Bullard, R., \& Evans, B. (eds) (2003). Just Sustainabilities: Development in an Unequal World. Cambridge MA: MIT Press

Agyeman, J. (2005). Sustainable Communities and the Challenge of Environmental Justice. New York: New York University Press.

Barnhardt, R, (2005). Indigenous Knowledge Systems and Alaska Native Ways of Knowing. Anthropology \& Education Quarterly, 36, 8. https://doi.org/10.1525/aeq.2005.36.1.008

Breildlid, A. (2009). Culture, indigenous knowledge systems and sustainable development: A critical view of education in an African context International. Journal of Educational Development, 29, 140. https://doi.org/10.1016/j.ijedudev.2008.09.009

Blackport, R., \& Kushner, P. (2017). Isolating the Atmospheric Circulation Response to Arctic Sea Ice Loss in the Coupled Climate System. Journal of Climate 30, 2163-2185 https://doi.org/10.1175/JCLI-D-16-0257.1

Blumm, Michael, C., \& Wood, Mary, C. (2015). The Public Trust Doctrine in Environmental and Natural Resources Law, 2d Edition Carolina Academic Press, Forthcoming. Available at SSRN: https://ssrn.com/abstract=2572802

Brundtland Report (1987). Report of the World Commission on Environmental and Development: Our Common Future. Retrieved from http://www.un-documents.net/our-common-future.pdf)

Bothun, G. D. (2017). Thinking About Sustainability: Issues and Themes for College Students (pp. 77-127) In: Davim J. (eds) Curricula for Sustainability in Higher Education. Management and Industrial Engineering. https://doi.org/10.1007/978-3-319-56505-7_6

Bothun, G., \& Chess, J. (2017). Climate Policy Caution: Past is No Guide to the Future. Available at

http://www.theenergycollective.com/gregbothun/2410926/climate-policy-caution-past-no-gui de-future

Bryden, H., \& Imawaki, S. (2001). Ocean Heat Transport. In G. Siedler, J. Church, \& J.Gould (Eds.). International Geophysics, 77, 455-475. 
https://doi.org/10.1016/S0074-6142(01)80134-0

Cheng, L., Trenberth, K., Fasullo, J., Boyer, T., Abraham, J., \& Zhu, J. (2017). Improved estimates of ocean heat content from 1960 to 2015. Science Advances, 3(3), e1601545. https://doi.org/10.1126/sciadv.1601545

Cordell, D., \& White, S. (2011). Peak Phosphorus: Clarifying the Key Issues of a Vigorous Debate about Long-Term Phosphorus Security. Sustainability, 3, 2027-2049.

https://doi.org/10.3390/su3102027

Cronon, W. (1996). The Trouble with Wilderness; Or, Getting Back to the Wrong Nature. Environmental History, 1(1), 7-28. https://doi.org/10.2307/3985059

Dahlman, L. (2015). Climate Change: Ocean Heat Content retrieved at:

https://www.climate.gov/news-features/understanding-climate/climate-change-ocean-heat-co ntent

David, A., \& Wright, G. (1997). Increasing Returns and the Genesis of American Resource Abundance, Industrial and Corporate Change, 6, 203-245,

https://doi.org/10.1093/icc/6.2.203

Del Ninno, C., \& Lundberg, M. (2005). Treading water: The long-term impact of the 1998 flood on nutrition in Bangladesh, Economics \& Human Biology, 3, 67-96.

https://doi.org/10.1016/j.ehb.2004.12.002

Durning, A. (1992). How Much is Enough? The Consumer Society and the Future of the Earth, In Stark, L (eds) The Worldwatch Environmental Alert Series, WW Norton \& Company. Retrieved at: http://ase.tufts.edu/gdae/CS/The\%20Consumer\%20Society.pdf

Descartes, R. (1635). Discourse on Method (best accessed and read at: https://plato.stanford.edu/entries/descartes/)

Demski, C., Capstick, S., Pidgeon, N. et al. (2017). Experience of extreme weather affects climate change mitigation and adaptation responses. Climatic Change, 140(149). https://doi.org/10.1007/s10584-016-1837-4

Friedman, M. (1985). Are Americans Becoming More Materialistic? a Look At Changes in Expressions of Materialism in the Popular Literature of the Post-World War II Era In Hirschman, E., and Moris, B.(eds) Advances in Consumer Research Volume 12, 385-387 retrieved at: http://acrwebsite.org/volumes/6420/volumes/v12/NA-12

Frölicher, T., Joos, F., Raible, C., \& Sarmiento, J. L. (2013). Atmospheric CO2 response to volcanic eruptions: The role of ENSO, season, and variability. Global Biogeochemical Cycles, 27(1), 239-251. https://doi.org/10.1002/gbc.20028

Griese, K., \& Polvani, L. (2014). The response of midlatitude jets to increased CO2: Distinguishing the roles of sea surface temperature and direct radiative forcing. Geophysical Research Letters, 41, 6863-6871. https://doi.org/10.1002/2014GL061638

Hansen, J. et. al (1985). Climate response times: dependence on climate sensitivity and ocean 
mixing. Science, 229, 857. https://doi.org/10.1126/science.229.4716.857

Hoffert, M., Callegari, A., \& Hsieh, C. (1980). The Role of deep sea heat storage in the secular response to climatic forcing, Journal of Geophysical Research, 85, 6667-6679. https://doi.org/10.1029/JC085iC11p06667

Huber, M., \& Sloan, C. (2000). Climatic responses to tropical sea surface temperature changes on a "greenhouse" Earth, Paleoceanography, 15, 443-450.

https://doi.org/10.1029/1999PA000455

Jaffe, S. (2017). Vulnerable Links in the Lithium-Ion Battery Supply Chain, Joule. 1, 225-228 https://doi: 10.1016/joule.2017.09.021

Lebow, V. (1955). Journal of Retailing available at: http://www.gcafh.org/edlab/Lebow.pdf

Lesk, C., Rowhani, P., \& Ramankutty, N. (2016). Influence of extreme weather disasters on global crop production. Nature, 529, 84-87. http://dx.doi.org/10.1038/nature16467

Levitus, S., Antonov, J., Boyer, T. and Stephens, C. (2000) Warming of the World Ocean. Science, 287, 2225-2229. https://doi.org/10.1126/science.287.5461.2225

Levitus, S. et al. (2012) World ocean heat content and thermosteric sea level change (0-2000 m), 1955-2010. Geophysical Research Letters, 39, L10603

https://doi.org/10.1029/2012GL051106

Madsen, H., Lawrence, D., Lang, M., Martkinkova, M., \& Kjeldsen, T. (2014). Review of trend analysis and climate change projections of extreme precipitation and floods in Europe Journal of Hydrology, 519, 3634-3650. https://doi.org/10.1016/j.jhydrol.2014.11.003

Maier, C. (1977). The politics of productivity: foundations of American international economic policy after World War II. International Organization, 31, 607-633.

https://doi.org/10.1017/S0020818300018634

Mann, M. et al. (2017). Influence of Anthropogenic Climate Change on Planetary Wave Resonance and Extreme Weather Events. Scientific Reports, 7, Article number: 45242. http://dx.doi.org/10.1038/srep45242

Merrill, T. (2008). Masters and possessors of nature review of Discourse on Method by René Descartes. New Atlantis, 19, 91-107

Mumford, L. (1928). The Theory and Practice of Regionalism. The Sociological Review, 20, nos. 1 and 2. https://doi.org/10.1111/j.1467-954X.1928.tb02897.x

Mumford, L. (1930a). The Drama in the Machines in Scribners Magazine.

Mumford, L. (1930b). Modern American Design In Leonard, R. and Glassgold, C (eds) American Union of Decorative Artists and Craftsmen, 9

Mumford, L. (1934). Technics and Civilization, Harcourt, Brace \& Company, Inc., New York. Retrieved at https://www.journals.uchicago.edu/doi/abs/10.1086/346930 


\section{Macrothink}

Environmental Management and Sustainable Development

ISSN 2164-7682

2018, Vol. 7, No. 3

Mumford, L. (1938). The Culture of Cities, Harcourt, Brace \& Company, Inc., New York https://doi.org/10.1002/ncr.4110271016

Nathan, R. (1944). Mobilizing for Abundance, McGraw-Hill.

Needham, A. (2014). Power Lines: Phoenix and the Making of the Modern Southwest, Princeton Univ. Press Stable. https://doi.org/10.1515/9781400852406

Nelson, R., \& Wright, G. (1992). The rise and fall of American technological leadership: The post war period in historical perspective, Journal of Economic Literature, 30, 1931-1964. persistent link: https://econpapers.repec.org/RePEc:aea:jeclit:v:30:y:1992:i:4:p:1931-64

Oxfam International Report (2013). retrieved at:

https://d1tn3vj7xz9fdh.cloudfront.net/s3fs-public/file_attachments/story/oxfam_annual_repor t_2013_-_2014_final.pdf

Pistone, K., Eisenman, I., \& Ramanathan, V. (2014). Observational determination of albedo decrease caused by vanishing Arctic sea ice. PNAS, 111, 3322-3326.

https://doi.org/10.1073/pnas.1318201111

Robock, A. (2000). Volcanic eruptions and climate. Reviews of Geophysics 38, 191-219 https://doi.org/10.1029/1998RG000054

Sax, J. (1970). The Public Trust Doctrine in Natural Resources Law: Effective Judicial Intervention, Mich. L. Rev., 68, 471. https://doi.org/10.2307/1287556

Schlosberg, D. (1999). Schlosberg, D Environmental justice and the new pluralism. The challenge of difference for environmentalism. Oxford, University Press

Schlosberg, D., \& Collins, L. (2014). From environmental to climate justice: climate change and the discourse of environmental justice. WIREs Clim Change, 5, 359-374.

https://doi.org/10.1002/wcc.275

Sen, A. (2009). The Idea of Justice. Allen Lane, London.

https://doi.org/10.1017/S095382081100046X

Speirs, J., Contestabile, M., Houari, Y., \& Gross, B. (2014). The future of lithium availability for electric vehicle batteries, Renewable and Sustainable Energy Reviews, 35, 183-193. https://doi.org/10.1016/j.rser.2014.04.018

Steffen, W., Crutzen, P, \& McNeill, J. (2007). The Anthropocene: Are Humans Now Overwhelming the Great Forces of Nature?. A Journal of the Human Environment, 36, 614-621 https:// doi:10.1579/0044-7447

Stenchikov, G. et. al. (1998). Radiative forcing from the 1991 Mount Pinatubo volcanic eruption. Journal of Geophysical Research, 103, 13837-13857.

https://doi.org/10.1029/98JD00693

Stott, P. (2016). How climate change affects extreme weather events, Science, 24, 1517-1518. https://doi.org/10.1126/science.aaf7271 


\section{Macrothink}

Environmental Management and Sustainable Development

ISSN 2164-7682 2018, Vol. 7, No. 3

Stroeve, J., Markus, T., Boisvert, L., Miller, J., \& Barrett, A. (2014). Changes in Arctic melt season and implications for sea ice loss. Geophysical Research Letters, 41, 1216-1225. https://doi.org/10.1002/2013GL058951

Tabuchi, K. (2018). 2017 Set a record for losses from natural disasters; It could get worse. New York Times, retrieved from https://www.nytimes.com/2018/01/04/climate/losses-natural-disasters-insurance.html

Tang, Q., Zhang, X., \& Francis, J. (2014). Extreme summer weather in northern mid-latitudes linked to a vanishing cryosphere. Nature Climate Change, 4, 45-50.

http://dx.doi.org/10.1038/nclimate2065

Thiele-Eich, I., Burkhart, K., \& Simmer, C. (2015). Trends in water level and flooding in Dhaka, Bangladesh and their impact on mortality. Int J Environ Res Public Health, 12, 1196-215. https://doi.org/10.3390/ijerph120201196

Trenberth, K., Fasullo, J., \& Balmaseda, M. (2014). Earth's Energy Imbalance. Journal of Climate, 27, 3129. https://doi.org/10.1175/JCLI-D-13-00294.1

Vidal, J., \& Adam, D. (2007). China overtakes US as world's biggest CO2 emitter, The Guardian, available at: https://www.theguardian.com/environment/2007/jun/19/china.usnews

Walan, P., Davidsson, S., Johansson, S., \& Höök, M. (2014) Phosphate rock production and depletion: Regional disaggregated modeling and global implications. Resources, Conservation and Recycling, 93(0). 178-187. https://doi.org/10.1016/j.resconrec.2014.10.011

Warlenius, R., Pierce, G., \& Ramasar, V. (2015). Reversing the arrow of arrears: The concept of "ecological debt" and its value for environmental justice. Global Environmental Change, 30, 21-30. http://dx.doi.org/10.1016/j.resconrec.2014.10.011

Wang, S., Li, Q., Fang, C., \& Zhou, C. (2016) The relationship between economic growth, energy consumption, and $\mathrm{CO} 2$ emissions: Empirical evidence from China, Science of the Total Environment, 542, 360. https://doi.org/10.1016/j.scitotenv.2015.10.027

Whitely, N. (1987). Toward a Throw-Away Culture. Consumerism, 'Style Obsolescence' and Cultural Theory in the 1950s and 1960s. Oxford Art Journal, 10, 3.

https://doi.org/10.1093/oxartj/10.2.3

Wigley, T. (2018). The Paris warming targets: emissions requirements and sea level consequences. Climatic Change, 147, 31-45. https://doi.org/10.1007/s10584-017-2119-5

Wilkinson, R., \& Pickett, K. (2009). The Spirit Level: Why equality is better for everyone. Allen Lane, Leadership and Policy in Schools, 11(1), 129-134.

https://doi.org/10.1080/15700763.2011.577928

Wood, M. (2014). Nature's Trust: Environmental Law for a New Ecological Age, Cambridge University Press.

World Bank Report (2008), retrieved at:

http://siteresources.worldbank.org/EXTANNREP2K8/Resources/YR00_Year_in_Review_En 
glish.pdf

World Commission on Environment and Development (1996). Our Common Future, retrieved at: http://www.un-documents.net/our-common-future.pdf

Yu, L., Weller, R., \& Sun, B. (2004). Mean and Variability of the WHOI Daily Latent and Sensible Heat Fluxes at In Situ Flux Measurement Sites in the Atlantic Ocean. Journal of Climate, 17, 2096. https://doi.org/10.1175/1520-0442(2004)017<2096:MAVOTW>2.0.CO;2

\section{Copyright Disclaimer}

Copyright for this article is retained by the author(s), with first publication rights granted to the journal.

This is an open-access article distributed under the terms and conditions of the Creative Commons Attribution license (http://creativecommons.org/licenses/by/3.0/). 